\title{
Teaching the Professions
}

\author{
By Jeffrey J. Williams
}

$\mathrm{O}$ ne of every five employed Americans is a professional. According to the U. S. Bureau of Labor Statistics, there are about 31,000,000 Americans who work in "Professional and related occupations"-22\% of those employed and $10 \%$ of the general population. That vies with "Sales and office occupations," enlisting 33,000,000, as the predominant occupational category as of 2011, and exceeds "Service occupations" $(25,000,000)$, "Production, transport, and moving occupations" $(16,500,000)$, and "Management" $(15,000,000)$. Even though professions no longer assure a secure career as they once had, professionals are not declining in number, and, conjoined under the general heading "Management, professional, and related occupations," the professional-managerial class (PMC), as Barbara and John Ehrenreich once labeled it, is the largest segment of American labor, with 52,000,000, or over $37 \%$ of those employed.

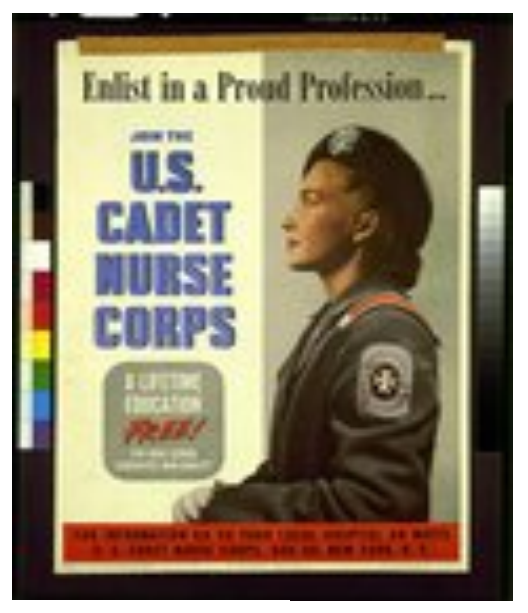

The central conduit into professions since the late nineteenth century has been higher education. The rise of professions coincides with the rise of the university in the United States. About $4 \%$ of the population had attended in 1900. The figure is $70 \%$ now; $30 \%$ have completed four years. There is some range in the Bureau of Labor Statistics category of professionals: it includes what we might consider beta professions, such as registered nurses and school teachers, along with alpha professions, like doctors and college professors. (Nurses' aides or dental assistants, however, are in the category of "Service occupations," and police and firemen fall into a subsection of "Protective services.") But the characteristic that links them is that they almost universally require a bachelor's degree and often a master's or other advanced degree, sometimes culminating with a test or other mode of inaugural accreditation (for instance, registered LIBRARY OF CONGRESS

Through the nineteenth century, the overwhelming majority of Americans worked in agriculture, and professionals were relatively rare. Educational and other professionals first appear in census data in 1850, numbering about 330,000 , or $2.5 \%$ of those employed, with most people-4,900,000 or $64 \%$-still working on farms. Most professions formalized their training and organizational structures during the later decades of the century, and by 1900 there were about 1,160,000 professionals ( $3.9 \%$ of those employed). They continued their rise over the next century, to $7.7 \%$ of the workforce in 1940 , about $10 \%$ by 1955 , over $15 \%$ by 1970 , and over $20 \%$ by 1990 . The twentieth century was the century of the professional.* even the humble profession of school teacher in most states requires a master's within five years of graduation). Higher education, particularly an advanced degree, usually separates the professionals from the non-professionals.

If we teach in a college or university, most of the students in front of us are there to become professionals and managers, whether doctors or nurses, engineers or information systems managers, accountants or school administrators. To confront their world and ours, I think that we should "teach the professions."

Teaching in an English department, I have developed a course called Narratives of the Professions that combines the basic frame of a literature survey with the history and sociology of professions, and I would like to tell you about nurses need four-year degrees as well as licenses, and 
it here. I have taught versions of the course at both state (the University of Missouri) and private universities (Carnegie Mellon), and at the undergraduate and graduate levels. While I concentrate on novels, I think one can teach a variant of this course in other disciplines, like history, sociology, or even business, combining a range of texts and information that compose a picture of the professions. Given the squeeze on professional jobs as well as the ambitions of our students, I think the course is especially germane now. It gives students equipment to understand the history and theory of professions as well as, more generally, the development of contemporary capitalism and our class system. When we think of teaching about class, we usually think about the working class, but this course provides another window onto class-indeed, the predominant class segment in the present United States.

The figure of the professional looms over contemporary American culture, in fiction, film, television, talk radio, news reporting, and advertising. The professional emerged as a significant figure in the AngloAmerican novel from the mid-nineteenth century on. The characters that people the early British novel are typically gentry, like Lady Booby in Henry Fielding's Joseph Andrews or Emma Woodhouse in Jane Austen's Emma, with yeoman farmers and servants in supporting roles. They usually inhabit the country and an agriculturally-oriented world. If there are professionals, they generally take the traditional role of clergy or military officers and serve at the bidding of the aristocracy or come from the aristocracy. By the second half of the nineteenth century, the main characters began shifting from gentry to shopkeepers, merchants, and professionals like doctors and lawyers, their position determined not by heredity, which is Joseph's and Emma's story, or aristocratic proximity, but by professional or mercantile status. They often inhabit growing towns or cities that swelled with the rise of industrialism. Professions carry a residual aristocratic ethos, but in the latter half of the century they became more formalized, requiring education, and professionals attain their standing through their work more than through position.

In Narratives of the Professions, I select novels from Anne Brontë to Dave Eggers that foreground characters who work, or aim to work, as professionals. Given its span, the course can serve to cover the latter half of the history of the novel, from Victorian to contemporary fiction. When I first started teaching it at Missouri in the late 1990s, I basically adapted it to a standard survey for English majors, in part because it gave the course a more coherent thematic thread than the usual parade of texts. (I have also added units on professionalism to theory surveys, which helped explain the post-World War II rise of criticism and theory.) Since then, I have expanded the history and sociological theory so that it is not just a sideline but essential to understanding the culture of the fiction. (It probably helped that I had moved to Carnegie Mellon, where we have a large MA program and I teach a good number of graduate seminars, so it is not unusual to read theory with novels. I have also used it in "special topics" humanities courses, and it seems to interest students from outside English as well as majors.) At present, I organize the course in three sections, according with the history of professions as well as the periods of the fiction: (1) the emergence of the professions in the mid-nineteenth century; (2) the formalization of professions in the modern period; and (3) the ambivalence toward and insecurity of professions in the contemporary moment.

Sometimes I start with historical readings to set out context and I usually assign the novels in chronological order, but of late I have happened upon an opening gambit that seems to work well, assigning Kazuo Ishiguro's 1988 novel The Remains of the Day first. The novel centers on Stevens, a butler in a British country house, who might seem an unlikely representative of a professional, but the word "profession" or "professional" occurs nearly 100 times in 240 pages and the novel is rife with Stevens' reflections on professionalism. It thus provides a good catalyst to discussion about what it means to be a professionalwhether he is one, the ambiguities of the term (to act professionally as opposed to belonging to a recognized profession), the training and credentialing required to attain professional standing, and the commitment to a calling. Set in midcentury, Remains of the Day exemplifies the transition to modern professionalism, with Stevens archaically maintaining aristocratic manners and wistfully remembering the heyday of the old regime, which has fallen away after World War II, supplanted by the more rationalized and meritocratic American system.

In addition, either during the first class session or due for the second, I have students write a short, informal paper giving their definition of a professional.

expressly ask them not to read any sources for it, just present their unadorned view. These papers provide a baseline to start with, and I save them to hand back at the end of the term so we

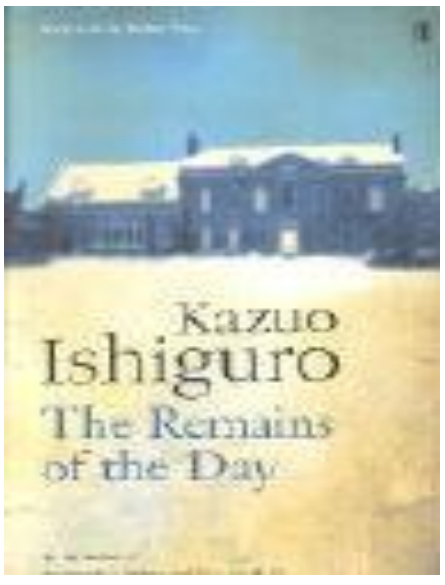
can see how students have changed, or not changed, their views. Though they might apologize for their lack of knowledge, students typically cover key attributes-that professions assume special knowledge, training, exams, and licenses or other credentials-and less flattering ideas, for instance that they form monopolies or that they evoke snobbism. Also, they bring up the fuzzy boundaries of professions-that one might call a cop a professional, or a prostitute-and that it simply means being paid, as when athletes go professional, or that it often connotes a manner rather than an occupation, as when we use it as an adjective and say a barista at Starbucks has a professional attitude. In the first or second class, I then outline their responses on the board in a spectrum from most technical to the fuzziest, and this gives us a kind of map to work with, so we can place Remains of the Day and subsequent readings on it, as well as see how historical and theoretical readings align with their views. 
The next step is readings on the history of the professions, from their roots in medieval guilds and clerical orders to twentieth century bureaucracies, to provide some hard facts before students read more fiction. I also use readings that compare professions in England, France, and the Unites States, for instance showing how the American system was more haphazard whereas the French system has been more centralized from the Napoleonic era on. One text I find particularly useful and take selections from is Paul Starr's The Social Transformation of American Medicine: The Rise of a Sovereign Profession and the Making of a Vast Industry, which recounts the development of medicine in the United States, from disorganization and hucksterism in the nineteenth century, to a more scientific basis and formalization in the twentieth and corporate bureaucracy by the end of the century. It furnishes a prototype of the trajectory of professions in the United States. (See the appendix for other examples of histories and theories.)

\section{As a counterpoint to Dr. Thorne, I might also assign Anne Brontë's Agnes Grey (1847), which shows the possibilities for women in the same era. The main character, Agnes, is a governess, one of the few career paths open to educated women, and depicts the unpleasant tasks she has to do in her tenuous role between servant and professional.}

Following up from the history, I might choose one or two novels that stage the emergence of the professions. One I have found useful is Anthony Trollope's Dr. Thorne (1858), the third in Trollope's "Chronicles of Barsetshire." Students sometimes complain about its length-500 pages-but it presents a good way to talk about the conventions of the Victorian novel, as well as the emergence of modern professions. At the beginning of the nineteenth century in England, medicine encompassed disparate groups of practitioners, such as apothecaries, surgeons, midwives, and physicians, without any overarching structure or much oversight. The British Medical Association (BMA) was founded in 1832, but it was not until the Medical Registration Act of 1858, the year of publication of $D r$. Thorne, that surgeons, apothecaries, and physicians became a single professional cohort. The novel shows some of the unevenness of medicine in the era, as competing doctors adhere to outmoded practices (the aptly named Dr. Fillgrave, for instance, frequently jeopardizes his patients with draughts he prescribes), whereas Dr. Thorne, the hero, advocates following scientific developments and thus suggests the new professional on the horizon.

As a counterpoint to Dr. Thorne, I might also assign Anne Brontë's Agnes Grey (1847), which shows the possibilities for women in the same era. The main character, Agnes, is a governess, one of the few career paths open to educated women, and depicts the unpleasant tasks she has to do in her tenuous role between servant and professional. The novel concludes with Agnes opening a school, demonstrating the shift from services performed primarily by family in the home, to services performed outside the home, in formal institutions, which in turn call for the expansion of the professions-with women staffing the beta, "caring" professions, like teaching and nursing, which at this point required little formal training. It also shows the path to independence that professions offer, and that Agnes and her mother attain at the end. There are of course a number of other novels one might choose-for instance, Dickens' Bleak House (1853) or Charlotte Brontë's The Professor (1857)-but I like how Agnes Grey illustrates this alternative early history of beta professions.

\section{The next step is readings on the history of the professions, from their roots in medieval guilds and clerical orders to twentieth century bureaucracies, to provide some hard facts before students read more fiction.}

The standard plan of literature courses, certainly of most courses I took, is a march of a novel or similar text per week. But I have become more committed to interweaving historical and theoretical readings, as I mentioned, to build our sense of the topic and also simply to alternate the pacing. One other thing that I have experimented with and strongly advocate is building presentations of short papers into the course, and requiring short papers. The customary requirement of a course, especially a graduate seminar, is a long research paper due at the end, but I have moved away from that model and have students write two or three short papers during the term, building to one slightly longer final one. It is unrealistic to expect a student to write several articlelength papers each semester (very few professors write this much, so why would it be an expectation for students?). Also, I find shorter papers more useful, amenable to presentation and to distribution, integrating students' research into the semester. For presentations, I set aside an entire class or block of classes. I used to schedule them at the end of class time, but I realized that, if someone had a paper due, they might not have read the assigned work, or if they had, their head was in the paper they just scrambled to write. From the audience side, class was usually winding down and the presentations seemed tacked on. So I prompt students to stage a miniconference, asking them to organize themselves on panels. I use these conferences to conclude each section, which creates a kind of pause between acts as well as emphasizing students' writing as a full-fledged part of the class. 


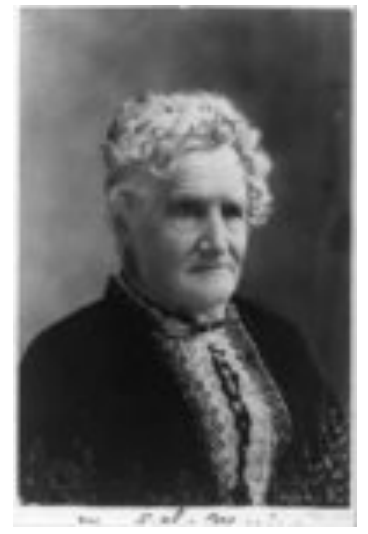

MRS. ESTHER MORRIS FIRST WOMAN JUDGE IN WYOMING TERRITORY. LIBRARY OF CONGRESS

For the first paper, I have students research a historical or sociological account of one profession, so their papers add up to a patchwork survey. I have had students write on the usual suspects like medical doctors or lawyers, less expected professionals like librarians or accountants, ambiguous ones like journalists, politicians, and sports players, and demi-professionals, like prostitutes and police. Undergraduates are often fascinated with demiprofessions, but seem to see professions from a distance, as still somewhat imaginary. Graduate students tend to see them as nearer and gravitate to those that relate to their scholarly interests. For instance, one grad student interested in drama researched the history of acting as a formal profession in the United States, from its sidelong status to the current Actors Guild. One Eastern European student told the story of "state professions" in the Soviet Union, and an Indian student reported on castes and professions in India. Several feminist students have recounted the history of midwives. And a number of students have been interested in literary professionals, such as artists, authors, journalists, and academics.

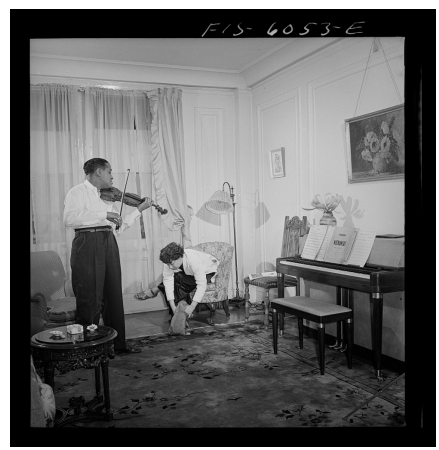

NEGRO PROFESSIONAL IN NEW YORK, 1942. LIBRARY OF CONGRESS

The second section of the course focuses on the establishment of the professions during the late nineteenth and early twentieth century. To provide some framing, I might start with readings on the theory of professions, largely from sociology, analyzing the structural features of and differences among professions that take hold in this period. One text I find essential is Magali Sarfatti Larson's classic The Rise of Professionalism: A Sociological Analysis, which schematizes how professions work: by attributing a need, by establishing a body of knowledge, by claiming a disinterested and altruistic purpose (a calling), and by credentialing those who can fulfill that need, thus gaining a monopoly on serving that need. We also read revisionary views, such as Andrew Abbott's, which focuses on the ways that professions negotiate their jurisdictions-say, how doctors take the jurisdiction of prescribing treatment, but have ceded the actual administering of most treatment to nurses.

A number of modern novels foreground the new professionals, and one I use is Joseph Conrad's Heart of Darkness, which received a great many interpretations in the 1950s and 60s about the descent into the subconscious or evil, and in the 1980 s and 90 s about colonialism and imperialism. Those are undeniable elements of the novel, but if we look at it in terms of class, it represents if not allegorizes the rising professions. This explains an odd feature of the narrative: other than Marlow, most of its characters are unnamed, or rather only named by their professional positions. For instance, in the frame, the characters include the Lawyer, the Director, and the Captain, who share the same training and respect each other because of their attention to a common calling. Then, in the tale Marlow tells, he privileges not just white characters but professionals. Critics have pointed out how the novel views Africans and women as inferior, but it also tends to ignore common deckhands and even the company executive in the Whited Sepulchre. As in Lord Jim, Marlow has a special bond with those who are "one of us," engaged as fellow professionals. For instance, he respects the starched accountant in the jungle because he carries out his professional tasks well, but has contempt for those who are only interested in monetary gain, like the Eldorado Exploring Expedition or the fleshy Englishman who faints on the trail and who remarks he is there "To make money, of course." He also eschews his aunt's assumption that there is a religious or moral motive; rather, he is faithful to the code of his profession and to other professionals, like Kurtz. The crux of the story is that Kurtz has transgressed not imperialism-after all, he gathers extraordinary amounts of ivory-but the code of professionalism.

Other texts that one might use include Thomas Hardy's Jude the Obscure (1895), which turns on the negative example of Jude, who shows talent and aspires to a literary education but is thwarted, or Virginia Woolf's Mrs. Dalloway (1925), which depicts the professional class in London at the turn of the century, with men becoming doctors, politicians, or colonial administrators, and the women their social managers behind the scenes.

Interwoven with the fiction, I bring in readings that trace the modern evolution of professionals, from what Steven Brint calls, in In an Age of Experts: The Changing Role of Professionals in Politics and Public Life, the social trustee model of service to the general public, into the specialized expert, serving a particular field. I always include Barbara and John Ehrenreich's still indispensable "The Professional-Managerial Class," which encapsulates the establishment and medial position of professionals in the twentieth century, between the ruling or owning class and the working class, as well as suggests its ambivalence of a class in-between.

For a second paper and class conference, I ask students to look at cultural images and write on a novel, film, television show, or other representation of a profession. Many choose films or shows about doctors or 


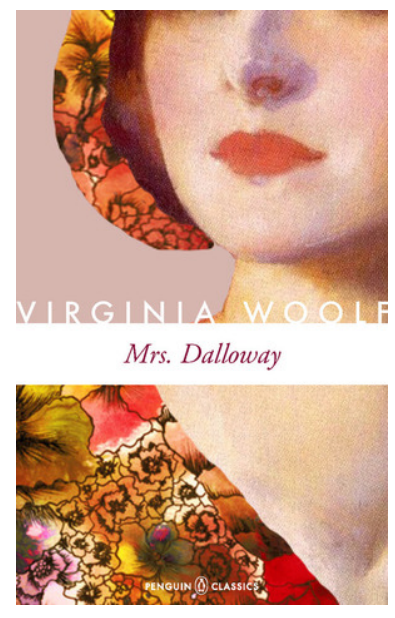

lawyers, such as Grey's Anatomy or House, which broadcast the special knowledge of doctors, as well as the pressures of their training. Occasionally students write on racier topics, such as the mafia as profession, in The Godfather or The Sopranos. Some graduate students choose novels and films on professors, with one student writing a striking paper on the TV show Community, that analyzed its medial status-for the teachers in a lesser school, and for the students who aspired to get a degree that would gain an entry into a profession.

From the first two assignments, I ask students to choose one and I compile and photocopy an anthology of their papers, with a cover and a table of contents. This is a trick I learned from composition. It occasionally induces students to roll their eyes, but I find it incredibly effective: students work hard to revise their papers for this modest but real form of publication, and then they have an actual hard copy of the work they and their compeers have done. Otherwise, it seems as if papers are disposable-handed in to the teacher, with a few comments on the page (and those are often unread-how many times have you put out a box of papers and had only a few of them picked up?). The tacit message is that papers are simply for the grade, whereas the presentations and the anthology reinforce that they are neither disposable nor mere tests, but have a use for other people, and also carry an obligation to other people. Their papers become a reference point for the class, and students will refer to them in subsequent discussions, just as they might a scholarly source, remarking "as Amy talked about in her paper...."

The third section of the course brings us up to the present, covering the period after World War II, and I turn to readings that illustrate the ill ease of contemporary professional standing. A selection from Barbara Ehrenreich's The Fear of Falling: The Inner Life of the Middle Class updates her idea of the Professional Managerial Class (PMC) and captures not only the structural position but the feeling and deep anxiety of current professional life. Andrew Ross's "The Mental Labor Problem" astutely analyzes "creative class," high tech jobs, that seem to allow freedom but actually colonize one's offtime, and that depart from old models of security to become piecework, perhaps with short-term excitement but without long-term security.

The fiction in the contemporary period tends to express an anxiety about or ambivalence toward professions. For example, contrary to the image of the complacent fifties, Richard Yates's Revolutionary Road (1961) stages the protagonist's deep ambivalence toward his job as a new PMC promotions man in New York. More recently, a novel like Helen Fielding's Bridget Jones's Diary (1996) documents the life and anxieties of a contemporary media worker. (Sex and the City would be another possibility.) From a different angle, Colson Whitehead's The Intuitionist (1999) and Apex Hides the Hurt (2006) both portray contemporary permutations of professions-in the former, an elevator inspector, and in the latter, a creative ad-man.

Of late, there has been a wave of novels that depict the disintegration of the PMC dream, such as Dave Egger's Hologram for the King (2012), which tells the story of a former bicycle company executive who loses out in the global market. In this segment, I might also assign novels that depict the academic world, such as Sam Lipsyte's The Ask (2010), which recounts the story of a failed academic who works in fundraising. The new professional is on precarious footing, contingent on generating money in the new global community. He no longer purveys expertise but works to leverage financial deals. Graduate students in particular respond to this segment, as they worry about jobless fates.

For the third paper, I ask students to write a proposal for a final paper, which can make use of their previous papers but synthesizes history, theory, and image, and which might extend to, say, 5 or so pages for undergrads and 8-10 for grad students. Some of the more ambitious students write comparative histories, for instance on the contest a century ago between neurology and psychology (psychology won), or tackle large views and critiques of professionalism, such as Anne Witz's Professions and Patriarchy or Richard Ohmann's English in America. The person who wrote on Community did a really good paper on the rise of community college a century ago (spearheaded by Robert Hutchins, who was president of the University

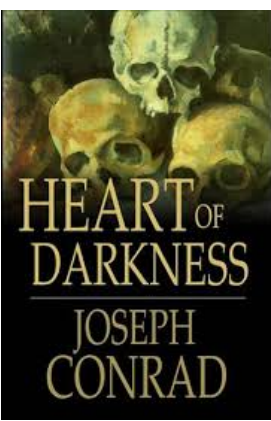
of Chicago), leading to the relatively rare depictions of community college in film or TV.

Obviously there are many ways that one could tailor and reshape this course. One could orient it entirely toward American literature, reading, say, Herman Melville's "Bartleby, the Scrivener" (1853), about the rise of office work and the financial sector, Frank Norris's McTeague (1899), about an uncredentialed dentist, Babbitt, and Revolutionary Road, continuing to recent works like The Intuitionist and Hologram for the King. Or one could orient it to film and television. And one could focus on particular professions-on, say, academics, or on doctors.

The one thing I would not change is the weaving together of history, theory, sociology, and political economy with fiction and other cultural representations. I developed this course in part as a corrective to the way I was taught, either in literature or in theory courses. They generally framed the novel or theory as an autonomous entity, with a self-contained history. Sometimes there was a recommended text, such as Walter Houghton's The Victorian Frame of Mind or Gerald Graff's Professing Literature, but it was in the foggy "background." To be sure, a straight literary history can help students gain a basic repertoire in literature or theory, but I now try to 
construct courses that strive for a genuine synthesis. This is not just to add the exotic spice of interdisciplinary leavening; rather, it is to show how these threads of history, analysis, and representation inherently link together and mutually bear on each other. The rise of the professions is not an adjacent topic but fundamental to modern culture.

In common usage, we often see theory as a "tool." This takes some of the mystique away from theory, but it also deracinates theory. It makes me picture a box of Snap-On automotive tools, so one might grab, say, a deconstructive socket out of the rack and snap it onto one's interpretive wrench. It assumes that theory is interchangeable, without much necessary connection to the object of study other than producing new interpretations. Professionalism is not just an approach that one can snap on to the novel, but has particular relevance to that cultural form, which tends to portray the world of the PMC, and to speak to the PMC as its prime audience. Teaching the professions puts priority on understanding how class is imagined and operates in our culture.

\section{Appendix}

Suggested Readings in the History and Sociology of the Professions

History

Burton J. Bledstein, The Culture of Professionalism: The Middle Class and the Development of Higher Education in America

History

Nathan O. Hatch, ed., The Professions in American

Bruce A. Kimball, The True Professional Ideal in America: A History

Elliott A. Krause, Death of the Guilds: Professions, States, and the Advance of Capitalism, 1930 to the Present

Keith A. Macdonald, The Sociology of Professions

Paul Starr, The Social Transformation of American Medicine: The Rise of a Sovereign Profession and the Making of a Vast Industry.

Theory

Andrew Abbott, The System of Professions: An Essay on the Division of Expert Labor

Steven Brint, In an Age of Experts: The Changing Role of Professionals in Politics and Public Life

Barbara and John Ehrenreich, "The ProfessionalManagerial Class," in Between Labor and Capital, ed. Pat Walker

Eliot Freidson, Professional Powers: A Study of the Institutionalization of Formal Knowledge

Magali Sarfatti Larson, The Rise of Professionalism: A Sociological Analysis

Contemporary

Barbara Ehrenreich, The Fear of Falling: The Inner Life of the Middle Class
Andrew Ross, "The Mental Labor Problem," in Ross, Low Pay, High Profile: The Global Push for Fair Labor

Richard Florida, The Rise of the Creative Class

* These statistics come from "Labor Force Characteristics by Race and Ethnicity, 2011," Report 1036 (Washington, D.C.: U.S. Department of Labor, 2012), particularly Table 8, "Employed people by detailed occupation...," pp. 20ff. They include "civilian noninstitutional population 16 years and older"-in other words, excluding those in the military or jail, as well as children. The other main categories are "Natural Resources, construction, and maintenance occupations," with 13,000,000, and, as part of "Management, professional and related occupations," "Business and financial operations," with 6,300,000. I round off to the nearest hundred thousand and adduce the percentages by my own calculation.

The first census was taken in 1820. These numbers come from Historical Statistics of the United States, 17891945, II (Washington, D.C.: Bureau of the Census, 1949), particularly Series D 1-10, "Labor Force-Persons 10 Years and Over Gainfully Occupied...," p. 63, and D 47-61, "Labor Force-Industrial Distribution of Gainful Workers: 1820$1940, "$ p. 64. Other than agriculture, the major type of work in the nineteenth century was "maker" or "manufacturer," which together constitute nearly half of the categories in the census of that time; see "Revising the Standard Occupational Classification System," Report 929 (Washington, D.C.: Bureau of Labor Statistics, 1999).

I take the percentages after 1940 from Ian D. Wyatt and Daniel E. Hecker, "Occupational Changes During the $20^{\text {th }}$ Century," Monthly Labor Review (March 2006), particularly from Chart 2, "Proportion of total employment of professional, technical, and kindred workers, 19102000 ," p. 38 (the review is published by the Department of Labor). As a point of comparison, agricultural workers slowly decreased to about $40 \%$ of those employed in 1900 , and sharply dropped after World War II, to only $1.6 \%$ now.

The expansion of higher education is a familiar fact, but we should also consider that high school as well as college was rare before 1900. Those with high school diplomas rose through the twentieth century, from $13.5 \%$ of those aged 25 or older in 1910 , to $24.5 \%$ in 1940 , to over $80 \%$ by 1990 . See Wyatt and Hecker, p. 43, who draw their data from the Digest of Education Statistics, published by the U. S. Department of Education's National Center for Education Statistics, http://www.nces.ed.gov/programs/digest.

\section{Notes}

I have designed a parallel course examining the history, theory, sociology, and politics of higher education, as well as the myriad cultural imaginations of it, in "Teach the University!" Pedagogy 8.1 (2008): 25-42.

As Jennifer Ruth aptly states, "The Victorian novel is crowded with professionals" ("The Victorian Novel and the 
Professions," in The Oxford Handbook on the Victorian Novel [Oxford: Oxford UP, 2013]).

Noel Parry and José Parry, "Social Closure and Collective Social Mobility," Industrial Society: Class, Cleavage, and Control, ed. Richard Scase (New York: St. Martin's, 1977), p. 115.

See my essay, "Conrad and Professionalism," in Approaches to Teaching Conrad's "Heart of Darkness" and "The Secret Sharer", ed. Hunt Hawkins and Brian W. Shaffer (New York: Modern Language Association, 2002), pp. 48-53.

See my essay, "Unlucky Jim: The Rise of the Adjunct Novel," The Chronicle of Higher Education (12 Nov. 2012): B12-14. 